\title{
DESEMPENHO TÉRMICO DO EDIFÍCIO DA FAU MARANHÃO EM DOIS MOMENTOS HISTÓRICOS
}

\section{THERMAL PERFORMANCE OF FAU MARANHAO BUILDING IN TWO HISTORIC MOMENTS}

\author{
Leticia de Oliveira Neves 1 \\ Universidade Estadual de Campinas, Campinas, Brasil, leticia@fec.unicamp.br \\ Rodrigo Dias Machado 2 \\ Universidade de São Paulo, São Paulo, Brasil, dias.rmachado@gmail.com \\ Rodrigo Cavalcante ${ }^{3}$ \\ Universidade Estadual de Campinas, Campinas, Brasil, rcdc81@gmail.com
}

\section{Resumo}

A edificação da FAU Maranhão, além de ser um importante patrimônio arquitetônico da cidade de São Paulo, é reconhecida por prover boa qualidade ambiental aos seus usuários. Tendo em vista que a edificação já abrigou usos distintos, propôs-se a, neste artigo, apresentar estudos que demonstrem a resposta térmica da edificação ao clima em que está inserida, em dois momentos históricos: logo após sua construção, quando seu uso era residencial, e atualmente, em que seu uso é acadêmico. Para isso, realizaram-se análises de desempenho térmico e da probabilidade de ocorrência de desconforto térmico em ambientes selecionados, por meio de pesquisa experimental baseada em simulações computacionais desenvolvidas no software EnergyPlus. Os resultados mostraram uma boa contribuição da elevada inércia térmica da construção na redução da oscilação das temperaturas internas e uma baixa ocorrência de períodos em desconforto térmico, demonstrando adequabilidade da edificação para as alterações nos padrões de uso e ocupação ocorridas ao longo de sua história. As taxas de renovação de ar obtidas por ventilação natural mostraram-se, no entanto, bastante inferiores no uso acadêmico, o que pode prejudicar a salubridade dos usuários, devido à taxa de ocupação mais elevada. Uma abordagem qualitativa dos resultados permitiu destacar questões importantes sobre o desempenho térmico e peculiaridades referentes à resiliência de edificações históricas que passam por modificações de uso ao longo de sua história.

Palavras-chave: Arquitetura bioclimática. Conforto térmico. Desempenho térmico. Inércia térmica. Edifício histórico.

\begin{abstract}
The FAU Maranhao building, beyond being an important architectural heritage of Sao Paulo city, is recognized for providing good environmental quality to its occupants. Since the building has already housed distinct uses, this paper presents studies that point out the thermal response of the building to the climate in which it is located, in two historical moments: right after its construction, which had a residential use, and nowadays, which has an educational use. To that end, thermal performance and thermal discomfort probability analyses were performed for selected rooms, through experimental research based on computer simulations using EnergyPlus software. Results indicate a good contribution of the construction's high thermal mass on reducing the indoor temperature fluctuation and a low occurrence of thermal discomfort periods, demonstrating the building's suitability to modifications on its pattern of use occurred during its history. In the educational use the air change rates obtained per natural ventilation, however, were lower than the residential use, affecting the healthiness of users due to higher occupancy rate. A qualitative approach of the results enabled to highlight important thermal performance issues and singularities about resiliency of historic buildings that changes its use over time.
\end{abstract}

Keywords: Bioclimatic architecture. Thermal comfort. Thermal performance. Thermal inertia. Historic building.

How to cite this article:

NEVES, Letícia de Oliveira; MACHADO, Rodrigo Dias; CAVALCANTE, Rodrigo. Desempenho térmico do edifício da FAU Maranhão em dois momentos históricos. PARC Pesquisa em Arquitetura e Construção, Campinas, SP, v. 7, n. 4, p. 211-224, dez. 2016. ISSN 1980-6809. Disponível em: <http://periodicos.sbu.unicamp.br/ojs/index.php/parc/article/view/8646323>. Acesso em: 12 maio 2017. doi:http://dx.doi.org/10.20396/parc.v7i4.8646323. 


\section{Introdução}

A edificação que atualmente abriga o curso de pósgraduação da Faculdade de Arquitetura e Urbanismo da Universidade de São Paulo (FAU-USP), conhecida como FAU Maranhão, consiste em um importante patrimônio arquitetônico nacional, sendo hoje um dos raros edifícios art nouveau da cidade de São Paulo (EDITORES, 2002). Sua arquitetura, tão diversa da produzida atualmente, ressalta aos olhos dos transeuntes das ruas do bairro Higienópolis (Figura 1).

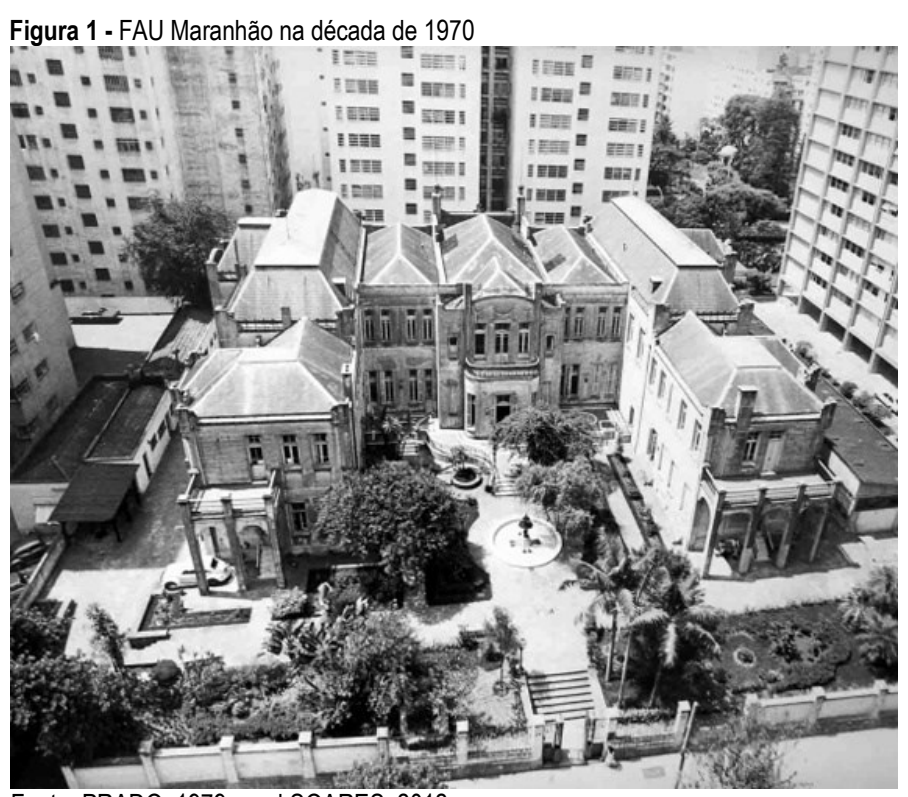

Fonte: PRADO, 1979 apud SOARES, 2012

Suas paredes espessas, seu pé-direito alto e suas esquadrias generosas são alguns dos elementos arquitetônicos que se destacam no antigo palacete e que são constantemente apontados como responsáveis pela qualidade ambiental e pelo conforto térmico que a edificação provê aos seus usuários. De fato, as edificações históricas são frequentemente reconhecidas como ambientalmente amigáveis (RESULI; DERVISHI, 2015), o que instiga à realização de uma análise mais aprofundada dessa edificação, de forma a compreender de fato a relação entre sua arquitetura e seu desempenho térmico.

Inicialmente construída para abrigar uma residência (Figura 2), a edificação foi doada à Universidade de São Paulo em meados do século XX, tendo seu uso e, consequentemente, suas cargas internas e padrões de ocupação bastante modificados. Tendo em vista esse fato histórico, pode-se traçar uma correlação com a afirmação de Segnini Junior (2008) que, ao discutir o projeto arquitetônico e a qualidade da edificação, afirma que é preciso considerar que arquitetura, enquanto abrigo, necessariamente pertence a um determinado momento histórico e, portanto, relaciona-se com a cultura da sociedade que a produz.
Figura 2 - Vila Penteado no início do século XX

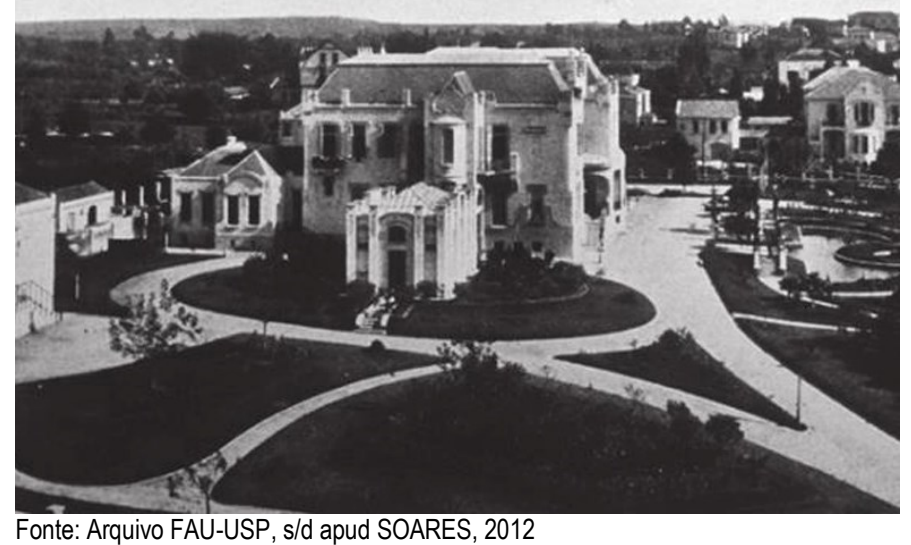

Em vista disso, torna-se interessante identificar as principais características da edificação no seu período inicial - uso residencial, e atual - uso acadêmico, bem como analisar sua resposta térmica nesses dois períodos de sua história, de forma a traçar um panorama de desempenho térmico do edifício, tendo em conta seu percurso histórico.

Nesse contexto, este trabalho tem por objetivo apresentar uma análise de desempenho térmico do edifício onde atualmente funciona o curso de pós-graduação da FAUUSP, em dois momentos históricos: entre 1930 e 1948, em que o edifício era denominado Vila Penteado e seu uso era residencial; e atualmente, em que o edifício é denominado FAU Maranhão e seu uso é acadêmico.

\section{Fundamentação}

O uso de simulações computacionais para avaliação do desempenho térmico de edificações é bastante comum na literatura especializada, pois permite avaliar diferentes alternativas de projeto, sejam elas opções do desenho arquitetônico ou de componentes construtivos (MENDES et al, 2005).

Em âmbito nacional, encontram-se alguns trabalhos na literatura especializada que avaliam o desempenho térmico de edificações históricas por meio de simulações computacionais. Vale mencionar o trabalho de Knop e Cunha (2012), que avaliaram o desempenho térmico de um edifício histórico localizado no centro de Pelotas, RS. $\mathrm{O}$ edifício foi originalmente construído para uso residencial e atualmente abriga uma instituição pública. A avaliação foi realizada por simulação computacional por meio do software Design Builder, sendo os resultados analisados por meio do modelo adaptativo de conforto térmico da norma ASHRAE 55 (2004). Nos resultados, os autores ressaltam a baixa probabilidade de ocorrência de desconforto térmico nos ambientes ocupados, mesmo após a mudança de uso da edificação, em função das técnicas construtivas, em especial das paredes de grande espessura, incomuns nos padrões construtivos atuais. 
Vale citar também o trabalho de Lima e Leder (2012), que analisaram o desempenho térmico de uma edificação que sofreu mudança de uso ao longo de sua história. Os autores avaliaram, por meio de simulações computacionais, a reabilitação de um imóvel de interesse cultural, exemplo da arquitetura modernista de João Pessoa, PB, para uso como habitação de interesse social. A análise teve enfoque nas condições de conforto ambiental, relativas a iluminação e ventilação naturais, e à eficiência energética.

Silva e Henriques (2015) analisaram o efeito da inércia térmica sobre o microclima interior de um edifício histórico em clima temperado, por meio de medições in loco. Os autores observaram que a envoltória de elevada inércia provocava um amortecimento e uma defasagem em relação ao exterior durante todo o período do inverno. Somente no fim da estação que se notou uma maior aproximação com as condições externas. A forte radiação solar no verão e a baixa resistência térmica da cobertura tornavam o efeito menos pronunciado no verão, mas ainda assim foi possível verificar um atraso considerável.

Internacionalmente, há estudos que avaliam o desempenho térmico de edificações históricas relacionando-as às questões de eficiência energética e sustentabilidade. Sedovic e Gotthelf (2011), por exemplo, demonstraram, por meio de estudos de caso, os benefícios econômicos, ambientais e sociais trazidos pelo bom desempenho de edifícios históricos. Segundo os autores, os edifícios históricos geralmente contavam com formas naturais e eficientes de aquecimento e resfriamento, o que refletia diretamente em sua geometria e na seleção de materiais de construção. Nesse sentido, elementos arquitetônicos como pé-direito alto, janelas operáveis, inclinação do telhado, paredes com elevada massa térmica e beirais amplos contribuíam para criar um ambiente naturalmente eficiente energeticamente.

Adhikari, Lucchi e Pracchi (2013) analisaram o desempenho energético de três edifícios históricos localizados na Itália, por meio de simulação computacional, de modo a avaliar a otimização dos requisitos de eficiência energética concomitantemente à preservação do valor cultural dessas edificações. Os autores afirmam que os problemas relacionados ao desempenho energético de edificações históricas permanecem sem resolução pois os critérios e métodos utilizados para avaliação de desempenho térmico, bem como os parâmetros selecionados para análise, são os mesmos das edificações contemporâneas. Nesse sentido, análises e intervenções em edificações históricas requerem maior conhecimento de história, técnicas de construção, estruturas e materiais, de modo a adequar-se às peculiaridades que envolvem esse tipo de estudo.

\section{Um breve histórico do edifício da FAU Maranhão}

O projeto da edificação, inicialmente denominada Vila Penteado, foi encomendado pelo conde Antônio Álvares Penteado ao arquiteto Carlos Ekman, em 1901. A construção da residência foi iniciada em 1902 e concluída no ano seguinte. O projeto tinha intenção de abrigar duas famílias: a família do próprio conde e a de seu genro, Antônio Prado Júnior. Além disso, havia uma ala adicional, destinada à governanta da casa (MARTINS, 2012) (Figuras 3 e 4 ).

Figura 3 - Planta do pavimento térreo da Vila Penteado

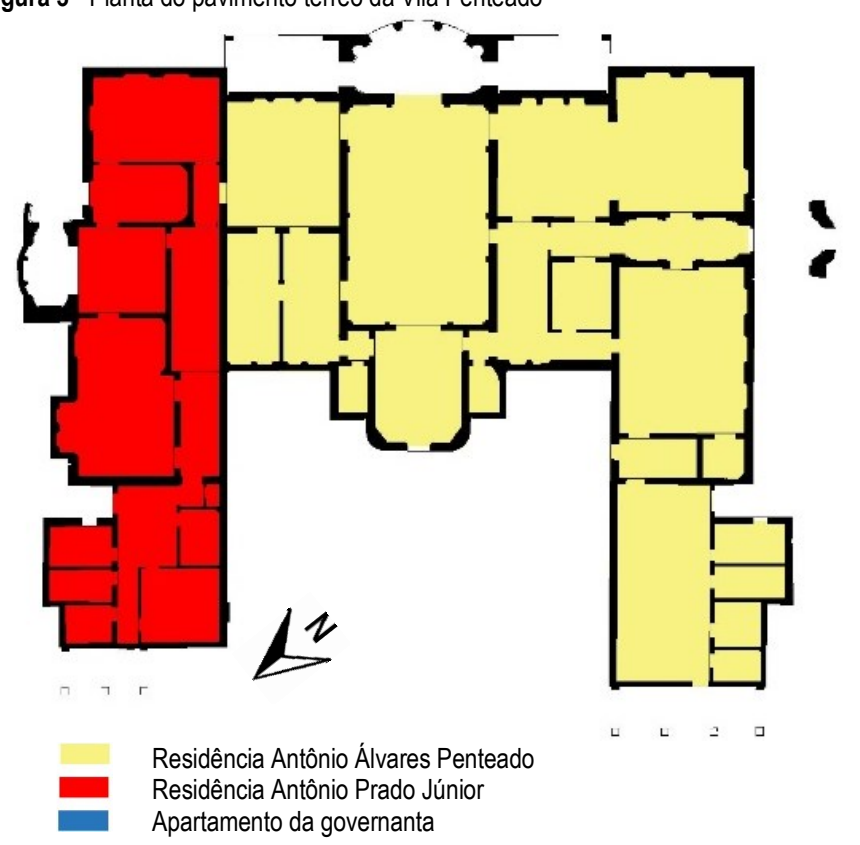

Fonte: Adaptado de FAU-USP (2016)

Figura 4 - Planta do pavimento superior da Vila Penteado

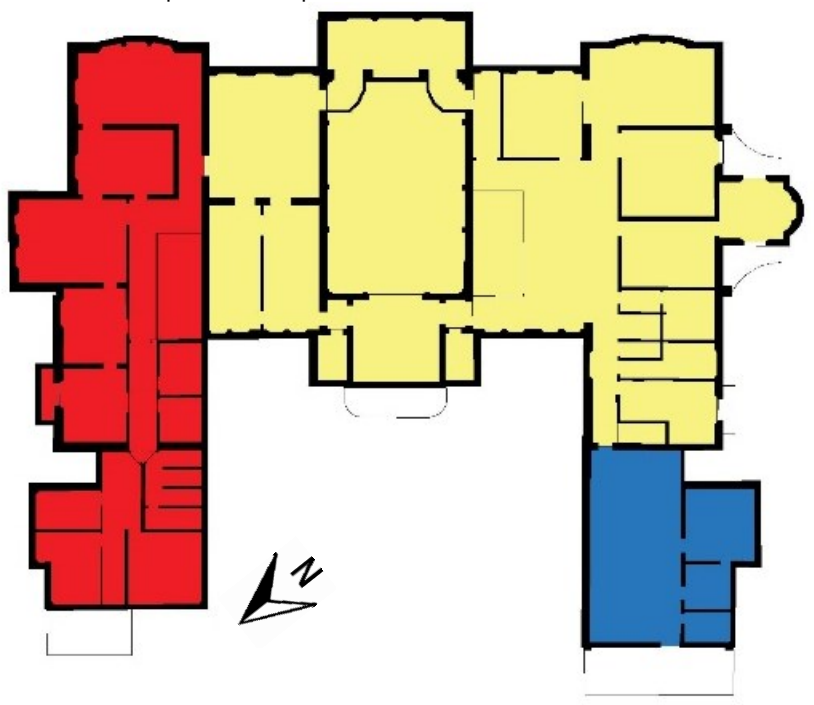

Fonte: Adaptado de FAU-USP (2016)

Após a morte do conde Álvares Penteado e de sua esposa, a Vila Penteado passou para a herança dos filhos; período em que a residência permaneceu fechada. Em 1946, a 
residência foi doada para a Universidade de São Paulo. A partir daí o edifício passou por reformas para se adequar ao novo uso: o pavimento superior foi adaptado para receber as salas de aula, a sessão de alunos e a diretoria; enquanto o pavimento inferior recebeu os ateliês de artes, pinturas e esculturas (SOARES, 2012).

Em 1969, o curso de graduação da FAU-USP mudou-se para o campus da Cidade Universitária. A partir de então, o edifício ficou desocupado até 1973, passando por uma grande deterioração. Somente após essa data, com a formação do curso de pós-graduação, que o edifício foi novamente ocupado, passando por novas obras de adaptação (SOARES, 2012).

Finalmente, em 1978, o edifício foi tombado pelo Conselho de Defesa do patrimônio Histórico, Artístico, Arqueológico e turístico do Estado de São Paulo (CONDEPHAAT) e pelo Conselho municipal de Preservação do Patrimônio Histórico, Cultural e Ambiental da Cidade de São Paulo (CONPRESP) (SOARES, 2012), sendo atualmente utilizado para abrigar o curso de pós-graduação da FAU-USP.

\section{Relação entre os elementos arquitetônicos e 0 desempenho térmico da edificação}

A Vila Penteado foi construída ao fim do período de transição da tecnologia construtiva da taipa para a de alvenaria de tijolos cerâmicos (MARTINS, 2012). As paredes do edifício são compostas por tijolo cerâmico com espessuras consideráveis (semelhantes às utilizadas em paredes de taipa), variando entre $30 \mathrm{~cm}$ e $50 \mathrm{~cm}$. Esse componente construtivo possui elevada inércia térmica, o que resulta em um elevado amortecimento da temperatura interna e em um atraso térmico significativo. Muitas edificações históricas empregam materiais de alta massa térmica em sua envoltória, o que pode contribuir na redução do consumo de energia com condicionamento artificial (RESULI; DERVISHI, 2015), premissa essa que se torna cada vez mais importante na atualidade.

De maneira análoga, o ático amortece e atrasa o fluxo de calor vindo da cobertura. Por sua grande altura (chegando a $5 \mathrm{~m}$ de pé-direito), o espaço vazio da cobertura recebe e dissipa o calor antes de atingir os ambientes ocupados, localizados logo abaixo.

A ventilação natural também é uma estratégia que merece ser mencionada. Os ambientes são ventilados por aberturas laterais de dimensões $1,84 \mathrm{~cm} \times 0,88 \mathrm{~cm}$, vedadas por esquadrias de quatro folhas, sendo duas na parte externa, compostas por venezianas de madeira, e duas na parte interna, compostas por folhas de vidro (Figura 5). O posicionamento das esquadrias favorece a ventilação cruzada nos ambientes que possuem aberturas em mais de uma fachada. Nos ambientes que possuem apenas uma fachada voltada para o exterior, há duas ou três esquadrias posicionadas lado a lado, em toda a extensão da parede, o que favorece maior movimento de ar por ventilação unilateral (Figura 6).

Figura 5 - Esquadrias das salas de aula da FAU Maranhão

Fonte: Arquivo próprio

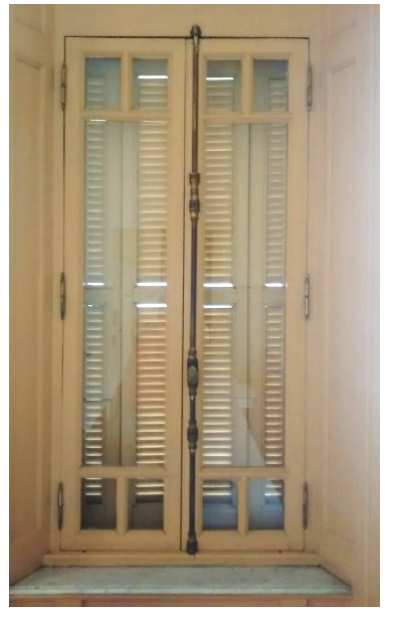

Figura 6 - Esquadrias das salas de aula da FAU Maranhão

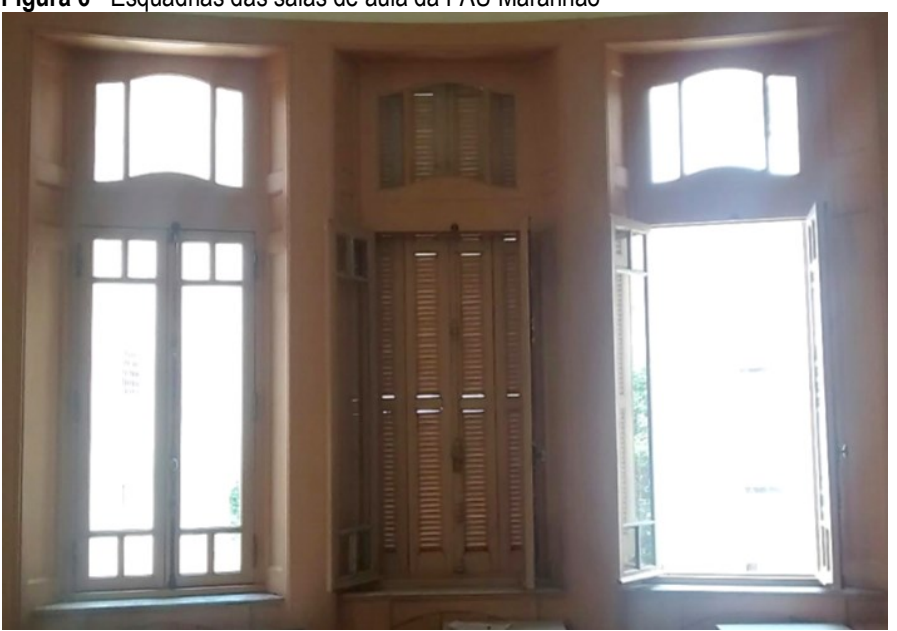

Fonte: Arquivo próprio

A edificação tem uma arquitetura marcada por diversos elementos de sombreamento, formado por beirais, sacadas, platibandas, marquises e recuos das esquadrias em relação ao limite externo da fachada, resultantes da elevada espessura das paredes. Tais elementos arquitetônicos e tantos outros detalhes construtivos da edificação a marcam por uma arquitetura diferenciada, reconhecida por sua importância histórica, mas até hoje pouco investigada no que diz respeito ao seu desempenho térmico.

\section{Metodologia}

Este artigo tem por objetivo realizar uma análise de desempenho térmico do edifício da FAU Maranhão em dois momentos históricos (usos residencial e acadêmico), por meio de simulações computacionais em softwares específicos. O desenvolvimento do trabalho inclui as seguintes etapas: 
(a) Configuração dos modelos de simulação: levantamento dos parâmetros de entrada de cada modelo, com base em dados obtidos da literatura especializada.

(b) Seleção de dados climáticos do município de São Paulo, de modo a representar os períodos históricos escolhidos para análise (1930 a 1948 e atual).

(c) Definição das condições de contorno: zoneamento térmico da edificação, descrição dos parâmetros de entrada relativos ao sombreamento do entorno e à ventilação natural.

(d) Análise e discussão de resultados: seleção dos ambientes internos e das variáveis de saída para análise dos resultados, identificação dos períodos de análise, geração de gráficos e avaliação dos resultados obtidos. Análise qualitativa de desempenho térmico da edificação, com destaque para as peculiaridades referentes à resiliência de edificações históricas que passam por modificações de uso ao longo de sua história.

\section{Configuração dos modelos de simulação}

A análise do edifício da FAU Maranhão foi realizada por meio de simulação computacional no software EnergyPlus, versão 8.3 (EERE, 2015), com base em arquivos climáticos do município de São Paulo e no comportamento térmico de alguns ambientes previamente selecionados para análise. A modelagem volumétrica da edificação foi realizada por meio do software SketchUp e do plugin OpenStudio.

Os parâmetros de entrada necessários para modelagem da edificação no EnergyPlus incluem: projeto arquitetônico, características físicas dos componentes construtivos, cargas internas e padrões de uso e ocupação de cada ambiente.

Para modelagem volumétrica da edificação, o projeto arquitetônico obtido em FAU-USP (2016) foi utilizado como referência (Figuras 3 e 4). Para modelagem das características físicas dos componentes construtivos, um levantamento detalhado dos componentes originais da edificação foi realizado com base nos dados disponibilizados por Soares (2012). Adicionalmente, calcularam-se os valores de transmitância térmica, capacidade térmica e fator solar referentes a cada componente construtivo (Tabela 1).

Como a edificação é tombada pelo patrimônio histórico, os componentes construtivos encontram-se, atualmente, em bom estado de preservação. Em vista disso, na análise da FAU Maranhão foram mantidos os mesmos componentes construtivos da construção original.

Para o levantamento dos dados originais de ocupação, padrões de uso e cargas internas do edifício da Vila Penteado fez-se necessário um resgate histórico de informações. Tal levantamento foi realizado com base em consulta à bibliografia especializada (NASCIMENTO, 2002; MAGNOLI, 2006; SILVA et al, 2007; MARTINS, 2012; SOARES, 2012). Definiu-se, como padrão de ocupação, uma pessoa por dormitório e duas pessoas por suíte, durante o período noturno, e duas pessoas por sala, durante o período diurno. Para a sala de festas, definiu-se também a ocorrência de um evento aos sábados, no período noturno.

\begin{tabular}{|c|c|c|c|c|}
\hline $\begin{array}{l}\text { Componente } \\
\text { construtivo }\end{array}$ & Materiais & $\begin{array}{c}\text { Transmitância } \\
\text { térmica } \\
{\left[\mathrm{W} / \mathrm{m}^{2} \mathrm{~K}\right]}\end{array}$ & $\begin{array}{c}\text { Capacidade } \\
\text { térmica } \\
{\left[\mathrm{kJ} / \mathrm{m}^{2} \mathrm{~K}\right]}\end{array}$ & $\begin{array}{c}\text { Fator } \\
\text { solar } \\
(\%)\end{array}$ \\
\hline \multirow{2}{*}{$\begin{array}{l}\text { Paredes } \\
\text { externas }\end{array}$} & $\begin{array}{c}\text { Tijolo } \\
\text { cerâmico } \\
50 \mathrm{~cm} \\
\end{array}$ & 1,08 & 703,0 & - \\
\hline & $\begin{array}{c}\text { Tijolo } \\
\text { cerâmico } \\
40 \mathrm{~cm} \\
\end{array}$ & 1,27 & 488.9 & - \\
\hline $\begin{array}{l}\text { Paredes } \\
\text { internas }\end{array}$ & $\begin{array}{c}\text { Tijolo } \\
\text { cerâmico } \\
30 \mathrm{~cm} \\
\end{array}$ & 1,38 & 442,8 & - \\
\hline Forro & Estuque & 2,72 & 45,67 & - \\
\hline Piso & Madeira & 1,19 & 211,68 & - \\
\hline Cobertura & $\begin{array}{c}\text { Peças de } \\
\text { ardósia }\end{array}$ & 3,85 & 100,5 & - \\
\hline $\begin{array}{l}\text { Esquadrias } \\
\text { (área } \\
\text { transparente) }\end{array}$ & $\begin{array}{l}\text { Vidro } \\
\text { comum }\end{array}$ & 5,70 & 12,6 & 87 \\
\hline
\end{tabular}

Fonte: Os autores

Com relação às cargas internas, não foi possível levantar informações precisas referentes às cargas de iluminação e de equipamentos. Em vista disso, como é de comum conhecimento o fato de que houve um aumento, nas últimas décadas, das cargas internas com iluminação artificial e utensílios domésticos, previu-se, para o modelo da Vila Penteado, uma carga reduzida em relação ao que encontramos hoje em um ambiente residencial: $2 \mathrm{~W} / \mathrm{m}^{2}$ para iluminação e $1,5 \mathrm{~W} / \mathrm{m}^{2}$ para equipamentos, igualmente distribuídos nos ambientes de uso permanente.

Para o caso da FAU Maranhão, o levantamento dos perfis de uso foi realizado com base na atual estrutura do programa de pós-graduação da FAU-USP. Para as salas de aula, foram consideradas turmas de 15 alunos cada, ocorrendo quatro aulas simultâneas no período matutino e seis aulas simultâneas no período vespertino, de segunda a sexta. A biblioteca e a secretaria funcionam de segunda a sexta das $8 \mathrm{~h}$ às $17 \mathrm{~h}$, com três funcionários na biblioteca e nove funcionários na secretaria. $\mathrm{Na}$ sala de defesas ocorre um evento por dia, no período vespertino, com ocupação estimada em oito pessoas. $\mathrm{O}$ edifício não funciona aos sábados e domingos.

Para as cargas internas de iluminação artificial, foi considerado um valor médio de $10,7 \mathrm{~W} / \mathrm{m}^{2}$ para todos os ambientes, o que corresponde à classificação nível $\mathrm{A}$ do Programa Brasileiro de Etiquetagem (PBE Edifica) para 
edificações escolares (INMETRO, 2013). Para equipamentos e cargas de tomada considerou-se um valor $1,5 \mathrm{~W} / \mathrm{m}^{2}$ para a biblioteca e a secretaria e um valor de 15 $\mathrm{W} / \mathrm{m}^{2}$ para a sala de informática, o que equivale a, aproximadamente, seis computadores em funcionamento simultaneamente. Para as salas de aula considerou-se uma potência total de $230 \mathrm{~W}$ por sala, o que equivale à potência média de um equipamento de projeção.

\section{Seleção de dados climáticos do município de São Paulo}

Para realização da análise de desempenho térmico da edificação para o período atual (FAU Maranhão), utilizouse um arquivo climático no formato EnergyPlus weather file (epw), do tipo Typical Meteorological Year (TMY), montado com base em dados climáticos registrados pelo Instituto Nacional de Meteorologia (INMET), para o período de 2001 a 2010 (RORIZ, 2012).

Para a análise da edificação no período residencial (Vila Penteado), sabe-se que a opção mais recomendável seria a de um arquivo climático montado a partir de dados representativos do período entre 1930 e 1948. Não há, porém, registros de dados horários de radiação solar anteriores a 1950, para a cidade de São Paulo ${ }^{1}$, o que inviabiliza a criação de um arquivo climático tratado para a análise desse momento histórico. Dessa forma, montouse um arquivo representativo da época, de modo a levar em consideração possíveis alterações nas variáveis climáticas, em relação à situação presente. Para isso, foram coletados dados climáticos do ano de 1950, junto ao Instituto de Astronomia, Geofísica e Ciências Atmosféricas da Universidade de São Paulo (IAG-USP).

Tem-se dado grande evidência, nos últimos anos, ao fenômeno do aquecimento global, suas consequências sobre as mudanças climáticas e seus impactos sobre o aumento da temperatura média da superfície terrestre. Soma-se a isso o fato do município de São Paulo ter sofrido, nas últimas décadas, um vertiginoso aumento populacional e, por consequência, uma intensa verticalização (MEYER; GROSTEIN; BIDERMAN, 2004).

De fato, ao comparar o arquivo climático atual (20012010) com o arquivo de 1950, observa-se um aumento de pouco mais de $1^{\circ} \mathrm{C}$ na temperatura de bulbo seco média e uma redução de cerca de $10 \%$ na umidade relativa média (Figuras 7 e 8).

As velocidades do vento no arquivo de 1950 são superiores ao atual, o que pode ser um indício tanto do aumento de densidade da massa construída e da verticalização que a cidade de São Paulo vem sofrendo, como pode ser resultante de um monitoramento realizado em uma área de menor interferência de obstáculos aos ventos. Vale lembrar que uma limitação importante do presente estudo é a ausência, no Brasil, de arquivos climáticos horários anuais com datas antigas (meados do século XX). Por consequência, o arquivo climático de 1950 representa um ano real, ou seja, não passou por um tratamento estatístico dos dados.

Figura 7 - Médias para temperatura de bulbo seco $\left({ }^{\circ} \mathrm{C}\right)$ e umidade relativa do ar $(\%)$ de São Paulo, arquivos de 1950 e de 2001-2010, respectivamente - junho.
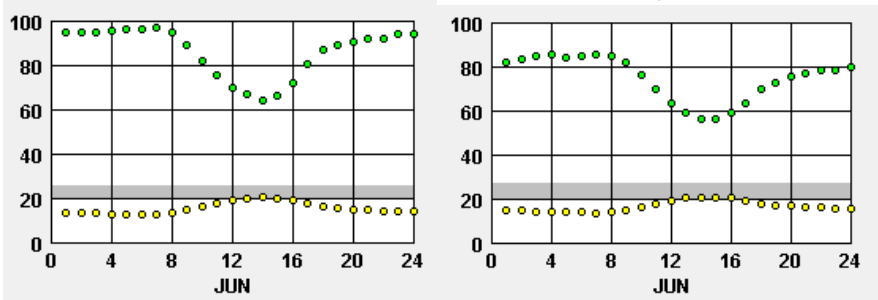

Fonte: Os autores

Figura 8 - Médias para temperatura de bulbo seco $\left({ }^{\circ} \mathrm{C}\right)$ e umidade relativa do ar $(\%)$ de São Paulo, arquivos de 1950 e de 2001-2010, respectivamente - dezembro.
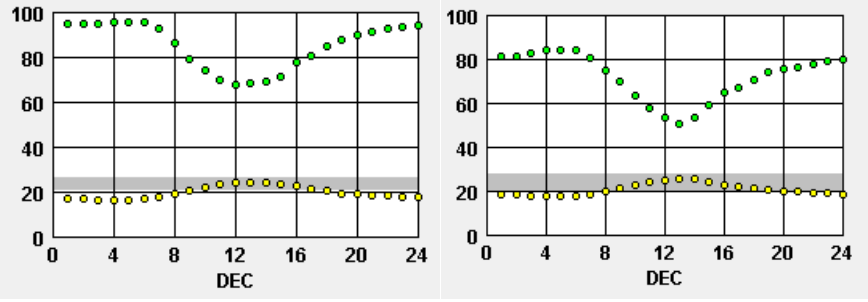

Fonte: Os autores

\section{Definição das condições de contorno}

$\mathrm{O}$ zoneamento térmico do modelo de simulação foi definido com base na orientação solar e no uso de cada ambiente (Figuras 9 e 10). Para realização da análise de desempenho térmico, foram selecionados três ambientes com usos distintos. Para cada momento histórico analisado, seus usos correspondem a:

- Ambiente 1: sala de festas (Vila Penteado) e sala dos espelhos (FAU Maranhão) (Figura 11).

- Ambiente 2: dormitório (Vila Penteado) e sala de aulas (FAU Maranhão) (Figura 12).

- Ambiente 3: sala de estar da governanta (Vila Penteado) e sala de informática (FAU Maranhão) (Figura 13).

Quando construída, a Vila Penteado não apresentava construções no entorno que provocassem sombreamento na edificação. Atualmente, a FAU Maranhão apresenta um entorno totalmente edificado, que interfere diretamente em seu sombreamento. Em vista disso, foram considerados dois cenários volumétricos para a análise: sem entorno edificado, para o caso da Vila Penteado (Figura 14) e com entorno edificado, para o caso da FAU Maranhão (Figura 15). Uma limitação importante de

\footnotetext{
${ }^{1}$ Informação obtida através do IAG-USP.
} 
modelagem que merece ser aqui destacada é a ausência de jardins e outras áreas verdes do entorno próximo no modelo, o que interfere diretamente nas trocas de calor latente da edificação com o entorno.

Para a modelagem de ventilação natural, as janelas foram mantidas abertas durante os horários de ocupação e fechadas durante os horários desocupados. Para determinação dos coeficientes de pressão, utilizou-se como referência a base de dados da Universidade Politécnica de Tóquio, para edifícios de baixa altura com beirais (KOOGEI, 2015). Para o coeficiente de descarga, utilizou-se um valor de 0,6 , conforme recomendado por Freixanet e Viqueira (2004). Optou-se também por utilizar uma área efetiva de abertura (vão livre para ventilação) de $80 \%$ da área total da esquadria, quando essa estiver aberta e disponível para ventilação natural.

Figura 9 - Zoneamento térmico do modelo de simulação - pavimento térreo

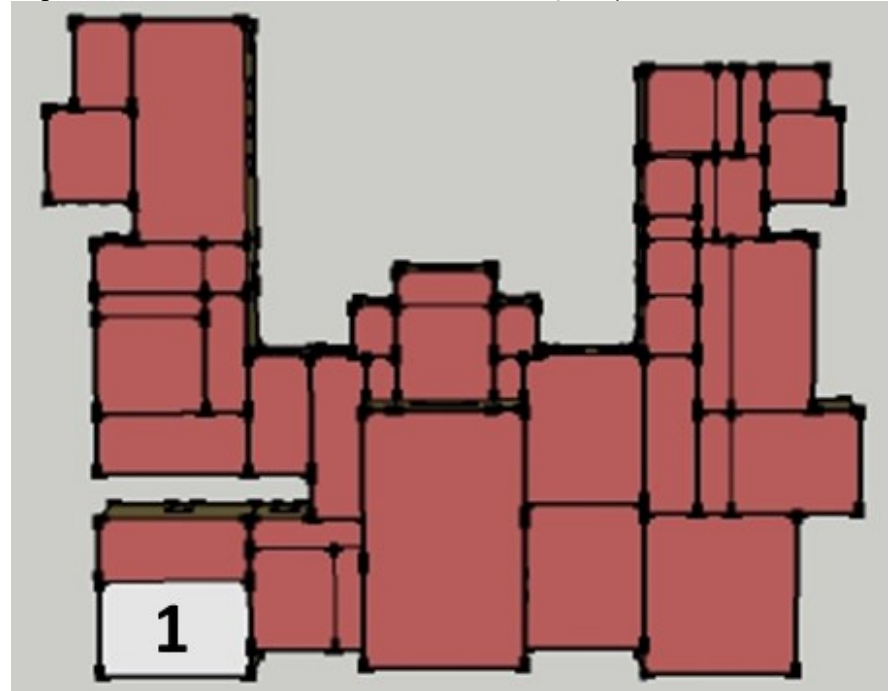

Fonte: Os autores

Figura 10 - Zoneamento térmico do modelo de simulação - pavimento superior

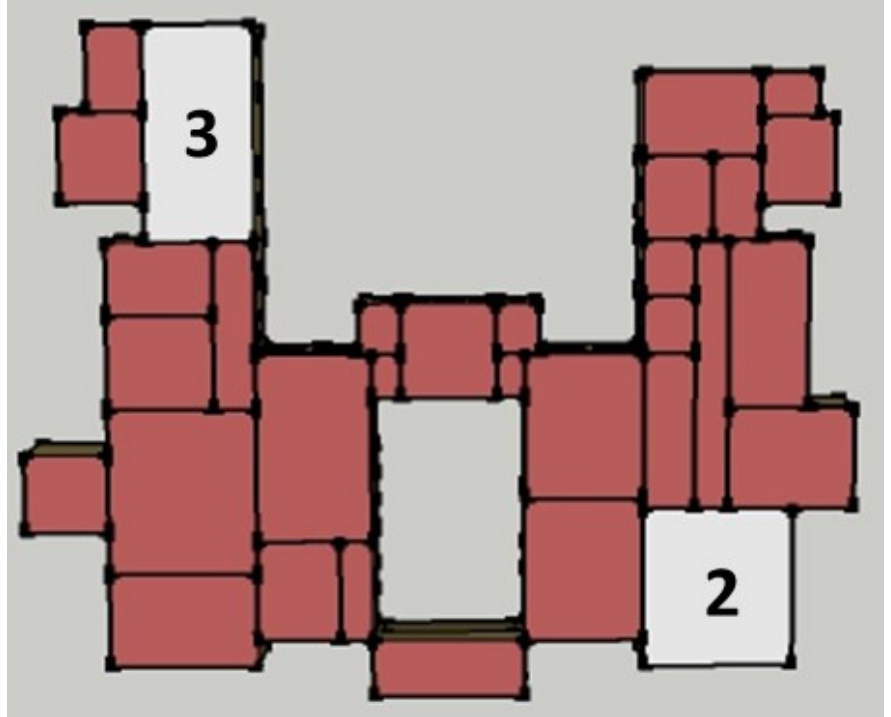

Figura 11 - Sala dos espelhos

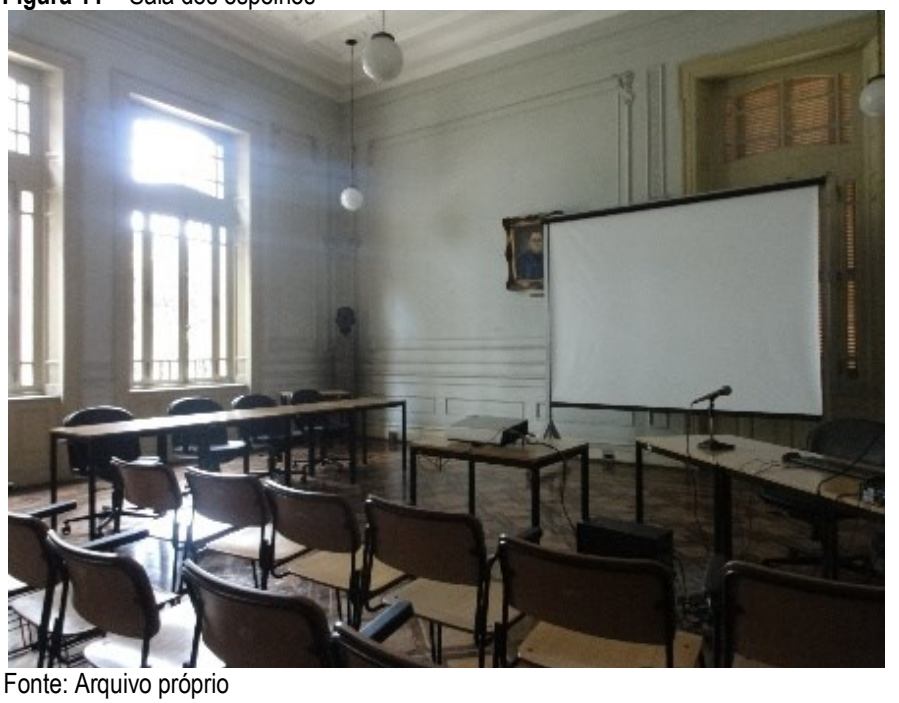

Figura 12 - Sala de aulas

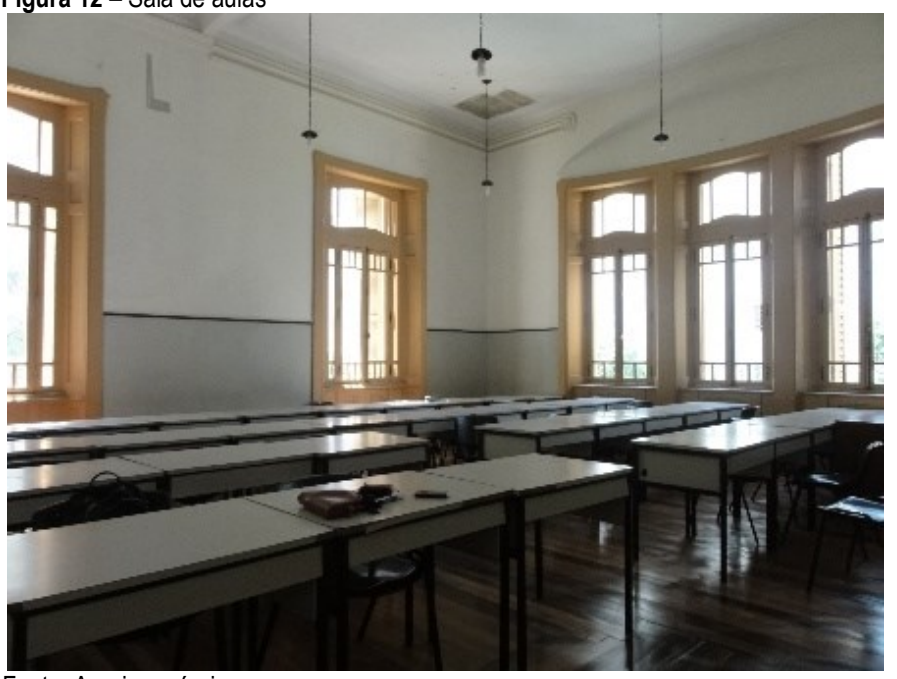

Fonte: Arquivo próprio

Figura 13 - Sala de informática

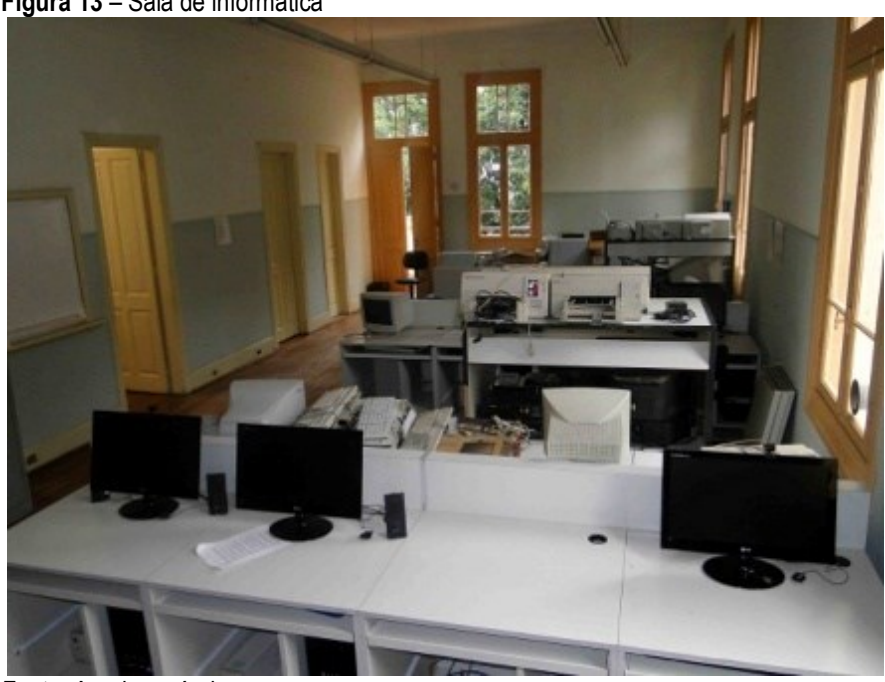

Fonte: Arquivo próprio

Fonte: Os autores 


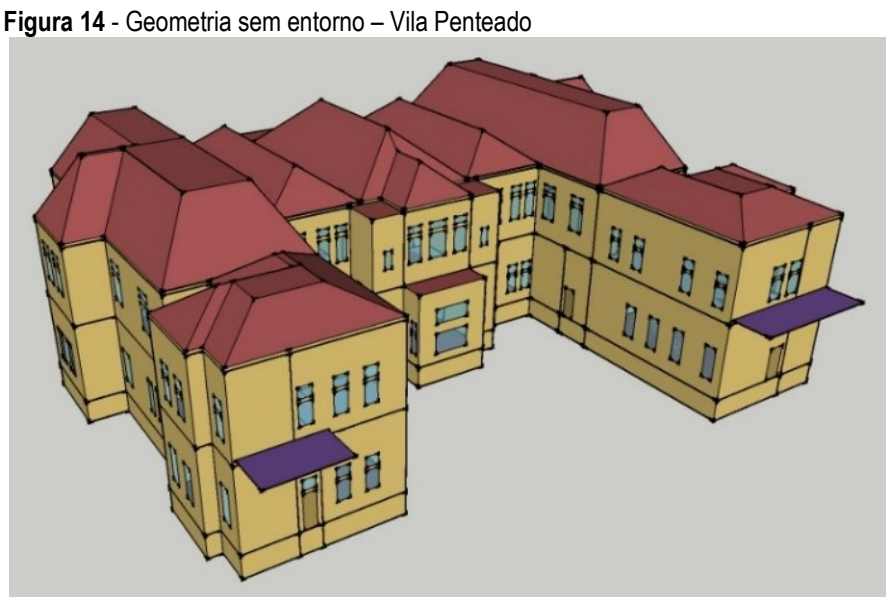

Fonte: Os autores

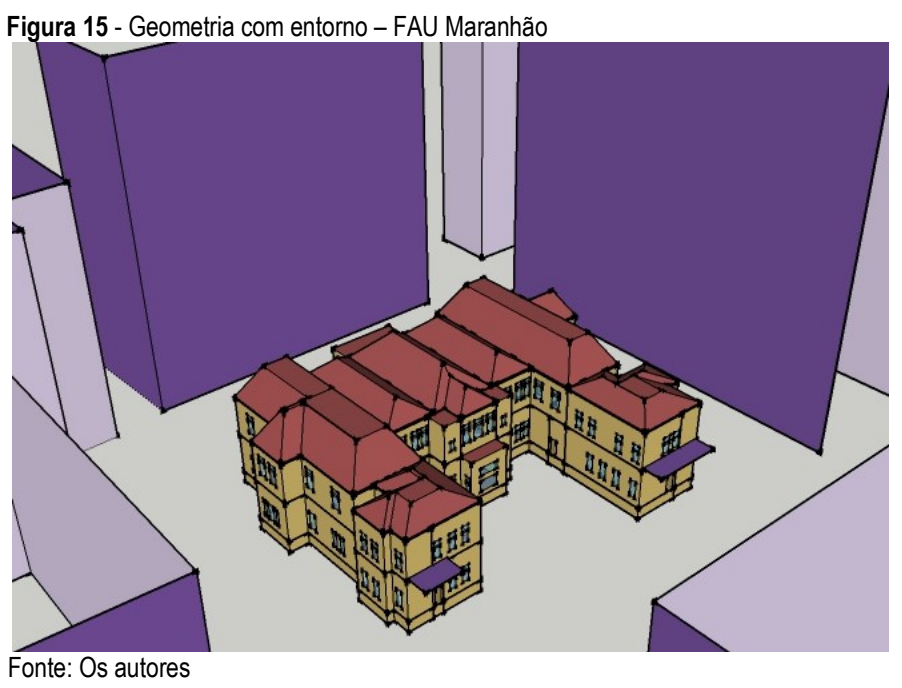

\section{Análise e discussão dos resultados}

As seguintes variáveis foram obtidas por meio das simulações termodinâmicas, para cada ambiente selecionado: vazão volumétrica $\left(\mathrm{Q} \mathrm{m}^{3} / \mathrm{h}\right)$, temperatura de bulbo seco (TBS ${ }^{\circ} \mathrm{C}$ ) e temperatura radiante média (TRM $\left.{ }^{\circ} \mathrm{C}\right)$. Os dados foram utilizados para realização de uma análise da resposta térmica da edificação, nos dois momentos históricos.

Além disso, considerou-se relevante adicionar uma análise anual de conforto térmico de seus usuários, para o cenário atual (FAU Maranhão), de forma a verificar os impactos que o atual tipo de uso da edificação traz ao conforto de seus ocupantes.

A metodologia adotada para realização da análise foi o modelo de conforto adaptativo da norma ASHRAE 55 (2013), considerando-se $80 \%$ dos ocupantes satisfeitos com as condições térmicas do ambiente. Calculou-se o número de horas ocupadas, no período de um ano, em que as condições ambientais dos espaços analisados estão em situação de conforto, de desconforto por frio ou por calor.
Os períodos de análise escolhidos foram uma semana do solstício de inverno e uma semana do solstício de verão, de forma a representar duas épocas do ano com características climáticas distintas.

\section{Resultados e discussões}

\section{Ambiente 1: Sala de festas (Vila Penteado) e Sala dos espelhos (FAU Maranhão)}

As Figuras 16 e 17 reproduzem a variação da velocidade dos ventos externos e a vazão volumétrica para o ambiente 1, durante as semanas de inverno e verão, para os arquivos climáticos de 1950 (Vila Penteado) e de 2001 a 2010 (FAU Maranhão). Para o caso da Vila Penteado (Figura 16), durante a semana de verão observou-se uma média de 9,4 renovações horárias nos horários ocupados do ambiente, em que as esquadrias estão abertas, proporcionando uma ventilação cruzada. Durante a semana do inverno, atingiuse uma média de 8,0 renovações horárias no ambiente. A velocidade do vento externo foi, em média, de $4,9 \mathrm{~m} / \mathrm{s}$ para o verão e de 3,3 m/s para o inverno (desvio padrão de 2,3, para ambos os casos).

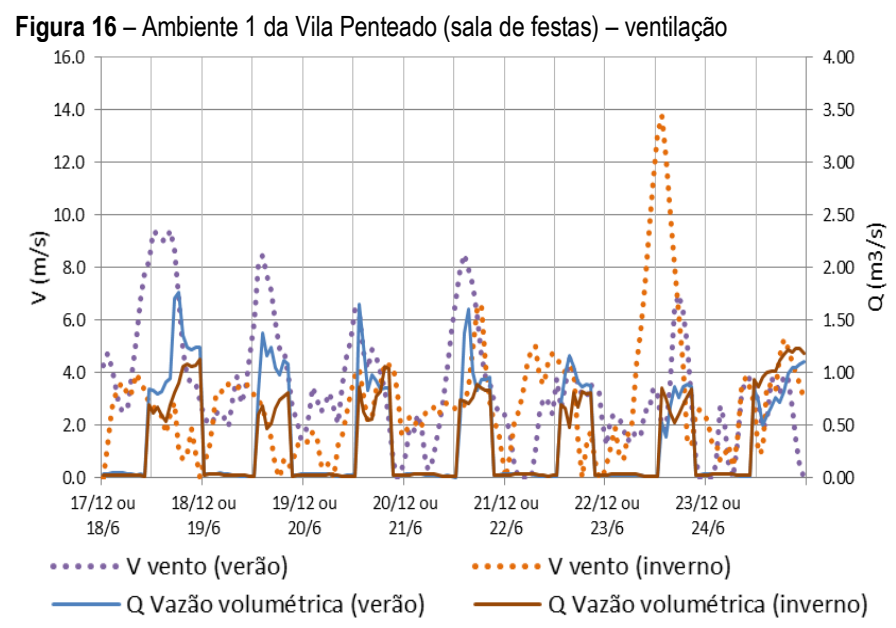

Fonte: Os autores

Figura 17 - Ambiente 1 da FAU Maranhão (sala dos espelhos) - ventilação

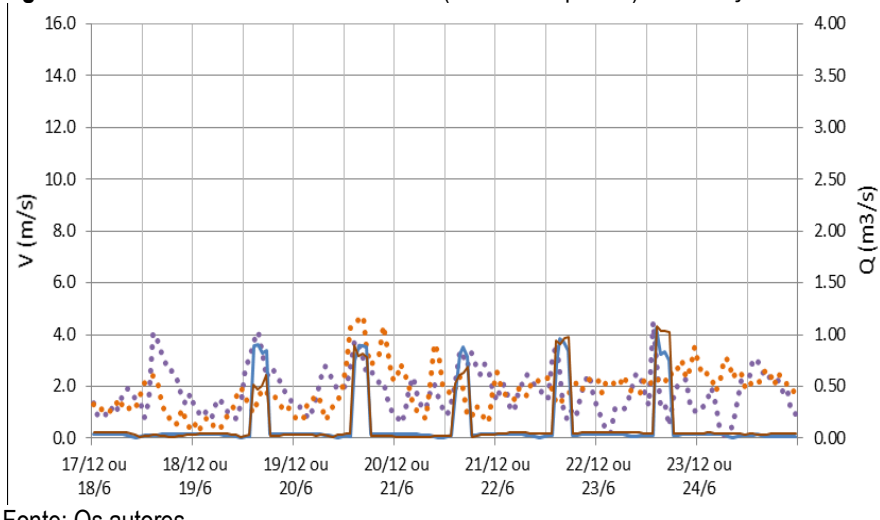

Fonte: Os autores

Para a FAU Maranhão (Figura 17), observou-se uma velocidade do vento externo mais baixa, com média de 3,3 
$\mathrm{m} / \mathrm{s}$ para o verão e de $2,3 \mathrm{~m} / \mathrm{s}$ para o inverno (desvio padrão de 0,6 e 1,1 , respectivamente). Consequentemente, o número de renovações horárias nos ambientes internos também foi menor, atingindo-se uma média de 4,8 renovações horárias nos horários ocupados do ambiente, durante o período de verão, e uma média de 7,7 renovações para o período de inverno.

Observou-se uma redução da eficácia da ventilação natural, em função das obstruções provocadas pelo entorno edificado. Tal resultado pode comprometer a qualidade do ar ambiente nos momentos de elevada taxa de ocupação.

As Figuras 18 e 19 reproduzem a variação dos dados de temperatura (TBS e TRM) para a semana de solstício de verão. No caso da Vila Penteado (Figura 18), a amplitude diária máxima foi de $13,8^{\circ} \mathrm{C}$ para as condições externas e de $6,8^{\circ} \mathrm{C}$ para o ambiente interno, o que indica uma forte interferência da elevada massa térmica da envoltória sobre a flutuação da temperatura no ambiente. Outro indicativo desse fato está nos resultados de TRM, que foram inferiores à TBS, em especial durante os picos de calor.

Figura 18 - Ambiente 1 da Vila Penteado - semana de verão

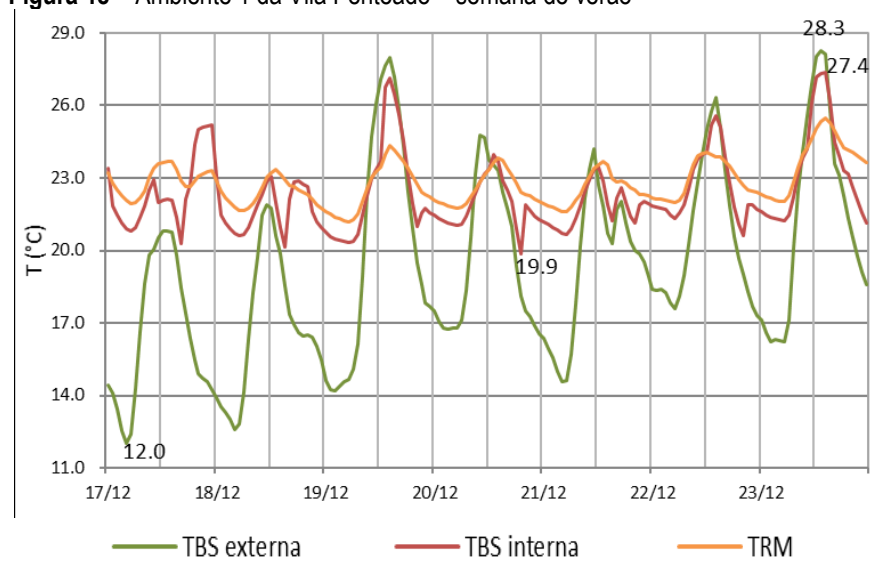

Fonte: Os autores

Figura 19 - Ambiente 1 da FAU Maranhão - semana de verão

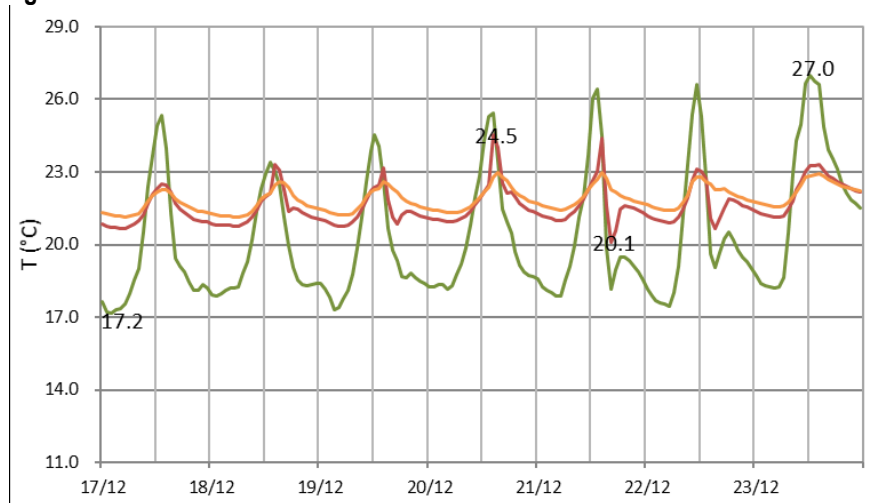

Fonte: Os autores

No caso da FAU Maranhão (Figura 19) também se pode observar, de forma ainda mais significativa, a interferência da elevada massa térmica da envoltória sobre a variação da temperatura ambiente, o que foi intensificado em razão das menores taxas de renovação de ar no ambiente.

Para ambos os casos, durante os períodos de ocupação em que as janelas estavam abertas para a ventilação natural - a TBS interna acompanhou a externa nos horários mais quentes do dia, o que se explica devido às elevadas taxas de renovação de ar no ambiente. Apesar do baixo amortecimento e atraso térmico resultantes, a temperatura interna manteve-se inferior à externa.

As Figuras 20 e 21 apresentam os resultados para o ambiente 1, no período de inverno. Para a FAU Maranhão (Figura 21), observou-se uma queda considerável na temperatura do ar externo a partir do meio da semana. A temperatura externa manteve-se a uma média de $18^{\circ} \mathrm{C}$ até o dia $21 / 06$, caindo para uma média de $13^{\circ} \mathrm{C}$ nos três últimos dias da semana. Julgou-se interessante manter essa semana para a análise, de forma a verificar a resposta térmica da edificação mediante uma alteração climática considerável. Um resultado semelhante pôde ser observado no trabalho de Silva e Henriques (2015), que confirmaram tal defasagem em relação ao exterior em um edifício histórico, por meio de medições.

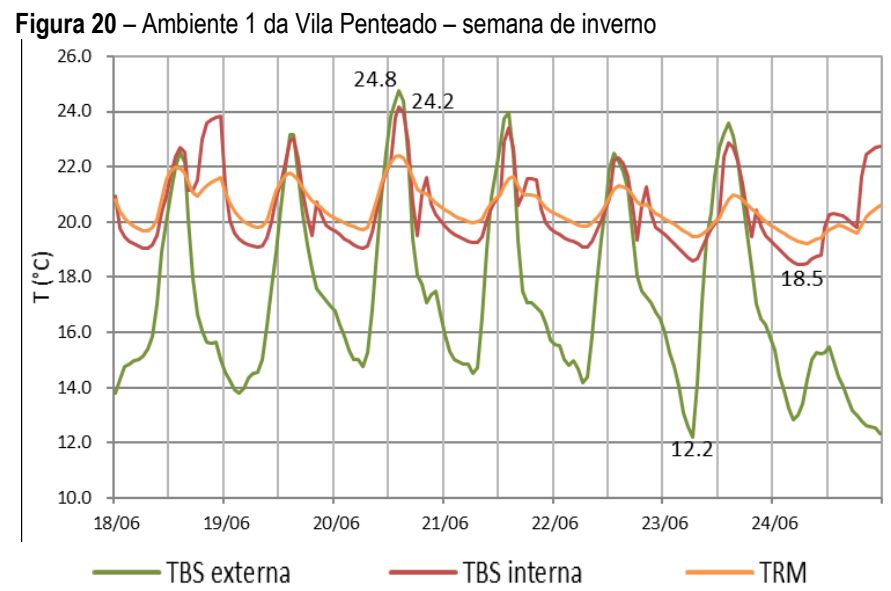

Fonte: Os autores

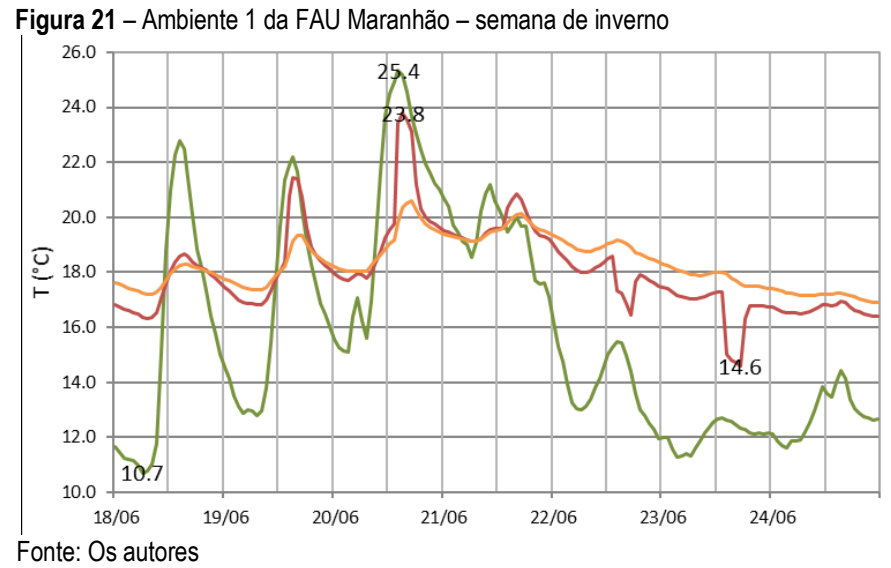

A análise anual de conforto térmico com base no modelo adaptativo, realizada para o caso da FAU Maranhão 
(Figura 22), mostrou uma ausência de desconforto por calor durante todo o ano e uma porcentagem significativa de desconforto por frio durante o inverno. Contribuíram para esse resultado o elevado amortecimento e a baixa amplitude térmica da temperatura interna, resultantes da alta inércia térmica da envoltória da edificação e do reduzido ganho de calor pela envoltória.

Figura 22 - Análise anual de desconforto para o ambiente 1 (FAU Maranhão)

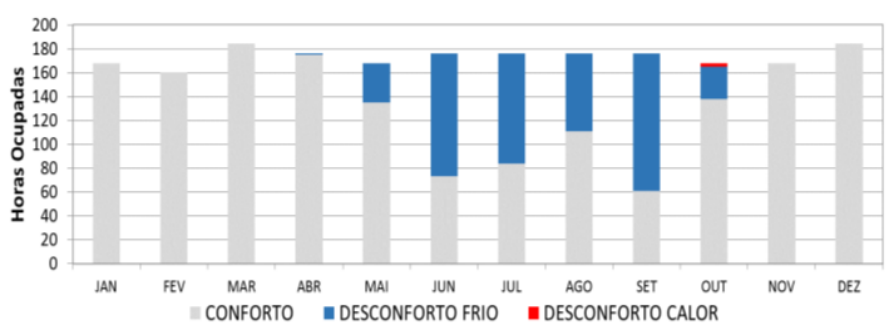

Fonte: Os autores

\section{Ambiente 2: Dormitório (Vila Penteado) e Sala de aulas (FAU Maranhão)}

Esse ambiente, localizado no pavimento superior da edificação, apresentou taxas de renovação do ar superiores às do ambiente 1, para os dois períodos analisados (Figuras 23 e 24). Ainda assim, observou-se uma redução significativa para o uso acadêmico em relação ao residencial, especialmente no período de verão, em que aos valores obtidos foram em média $25 \%$ inferiores.

Assim como no ambiente 1, pôde-se observar, para os dois períodos históricos analisados, uma redução considerável na amplitude térmica da temperatura interna, em relação à externa (Figuras 25 e 26). Os elevados valores de taxas de renovação do ar contribuíram para que a temperatura interna se mantivesse próxima à temperatura externa, durante os horários ocupados do ambiente.

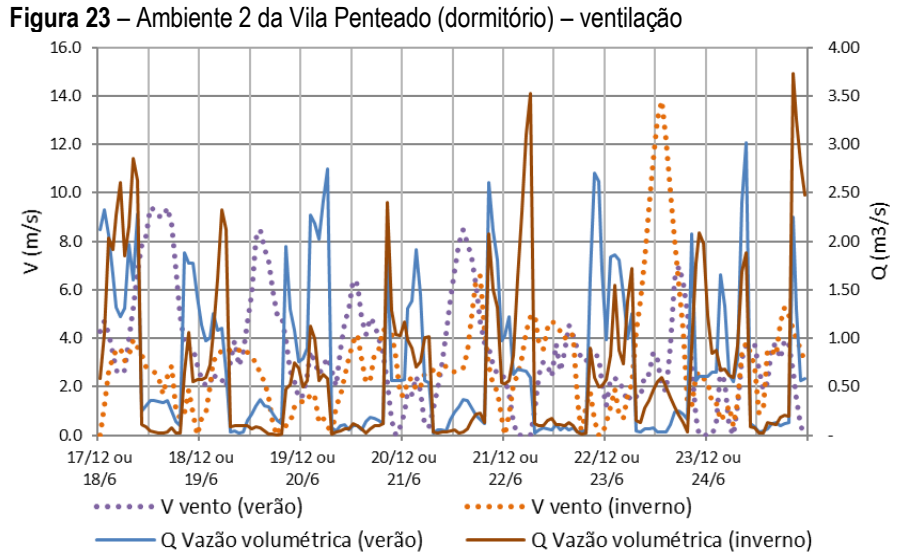

Fonte: Os autores

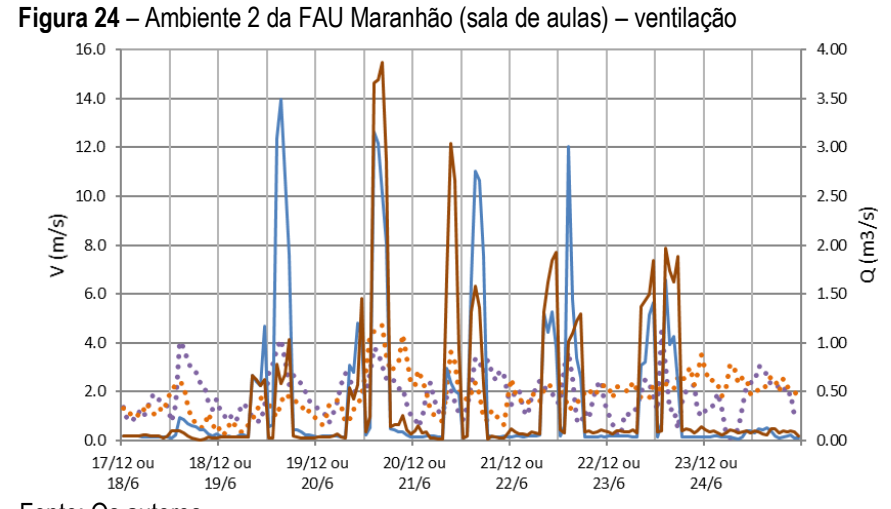

Fonte: Os autores

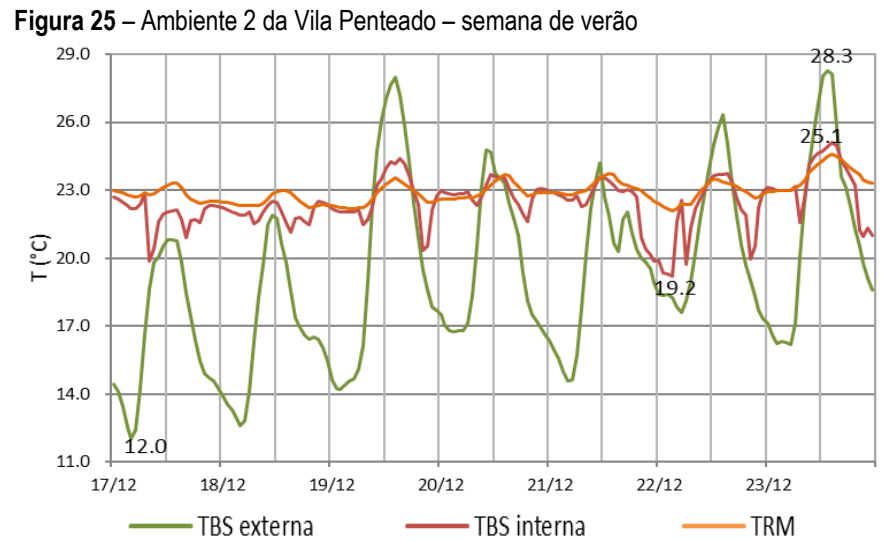

Fonte: Os autores

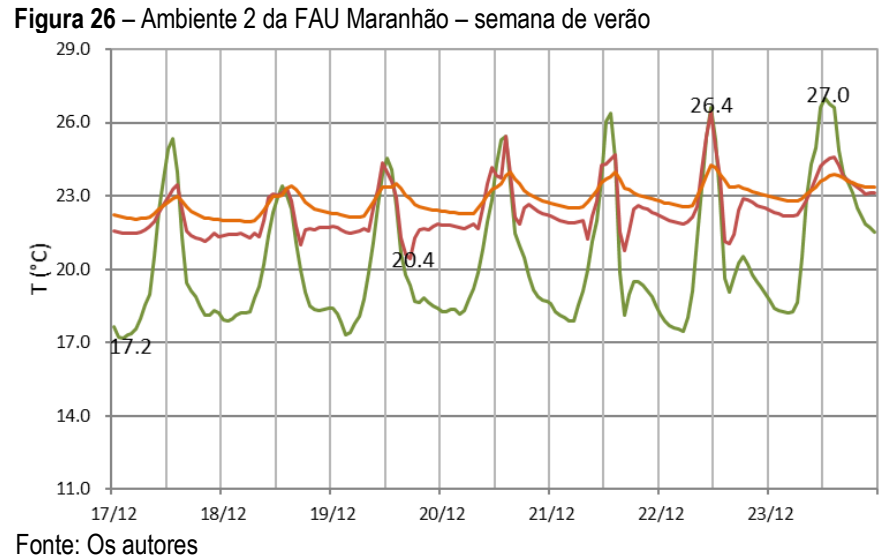

Em ambos os casos, a temperatura interna não acompanhou a temperatura externa no período noturno. Apesar de haver redução das cargas externas e internas nesses horários, o fechamento das janelas e a inércia da construção contribuíram para menor oscilação das temperaturas internas.

No caso da FAU Maranhão, a elevada carga interna, resultante principalmente da alta taxa de ocupação da sala de aula, contribuiu para a ocorrência de alguns períodos curtos de desconforto por calor, que podem ser observados na análise anual de desconforto térmico (Figura 27). Esses períodos coincidiram com os meses dos equinócios, que são os meses em que há maior incidência de radiação solar 
nas fachadas desse ambiente. Dadas as respectivas diferenças climáticas e construtivas, em âmbito geral é possível correlacionar tais resultados com os obtidos por Knop e Cunha (2012), em que se ressaltam as técnicas construtivas com paredes de elevada inércia contribuindo positivamente para o conforto térmico, mesmo após a mudança de uso da edificação.

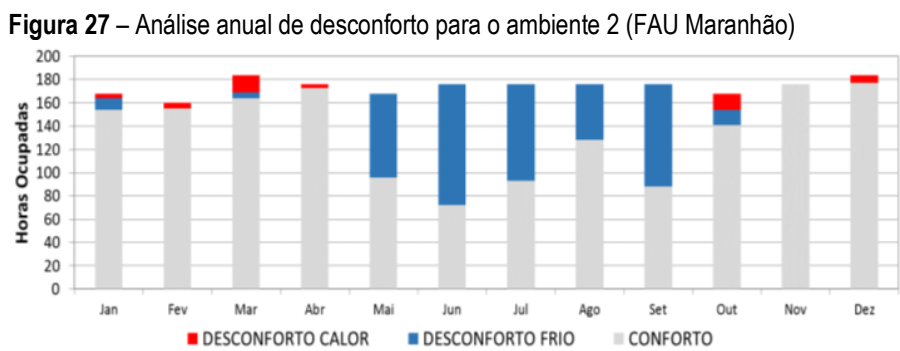

Fonte: Os autores

\section{Ambiente 3: Sala de estar (Vila Penteado) e Sala de informática (FAU Maranhão)}

O ambiente 3, também situado no pavimento superior, apresentou taxas de renovação do ar horárias inferiores ao ambiente 2 (Figuras 28 e 29), por estar em posição contrária à direção predominante dos ventos (Sudeste). No caso da FAU Maranhão, os valores de renovação horária do ar foram em média $43 \%$ inferiores aos obtidos para a Vila Penteado.

As Figuras 30 e 31 trazem os dados de TBS e TRM para a semana de solstício de verão. Para a FAU Maranhão (Figura 31), ressalta-se a TRM próxima à TBS durante todo o período, inclusive durante os picos de calor, em virtude do ganho mais elevado de calor nesse ambiente, devido principalmente às cargas internas, por se tratar de uma sala repleta de computadores.

Figura 28 - Ambiente 3 da Vila Penteado (sala de estar) - ventilação

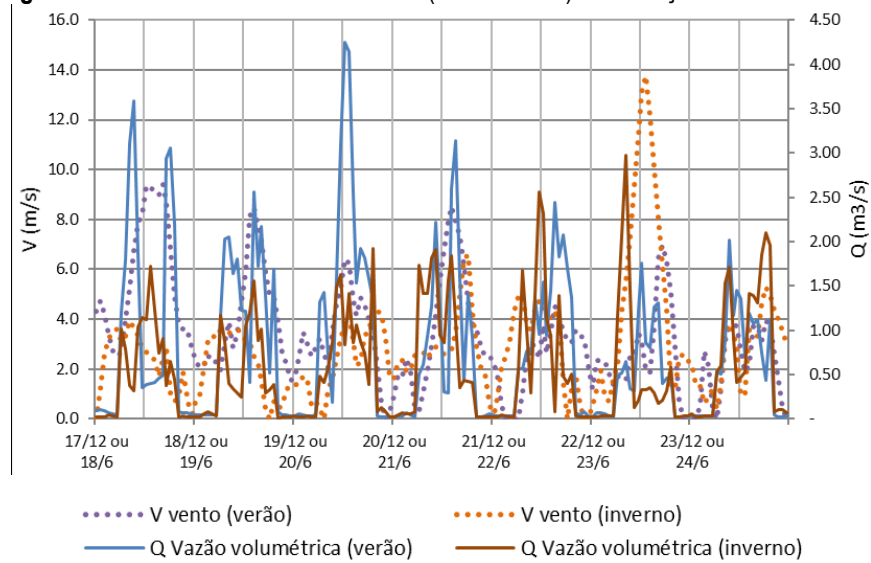

Fonte: Os autores

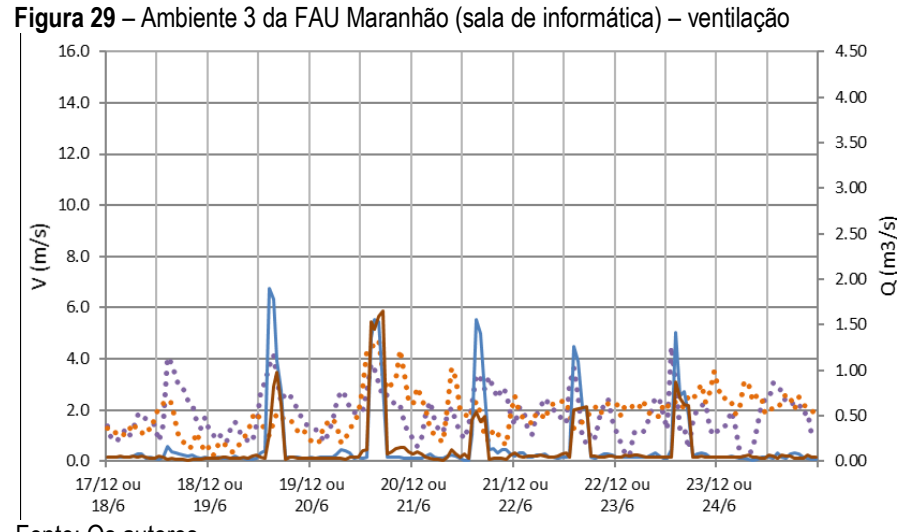

Fonte: Os autores

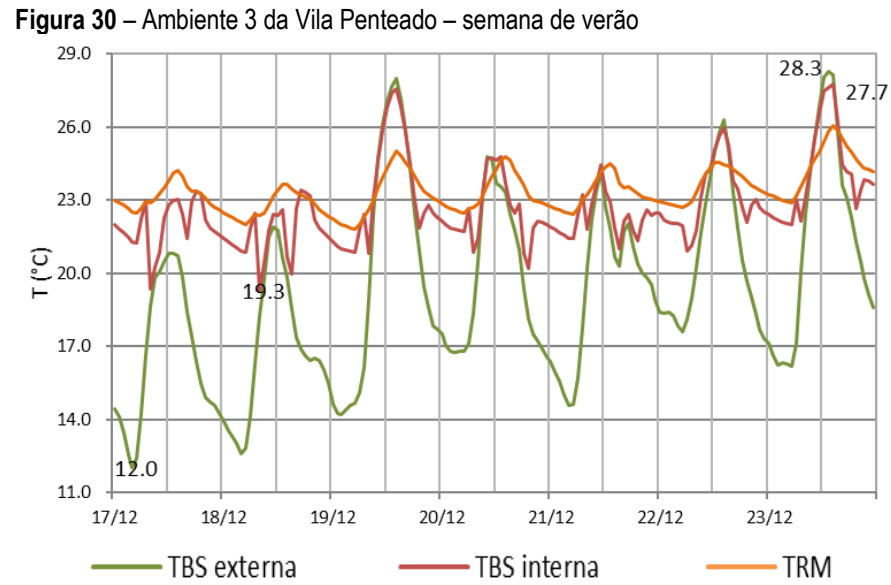

Fonte: Os autores

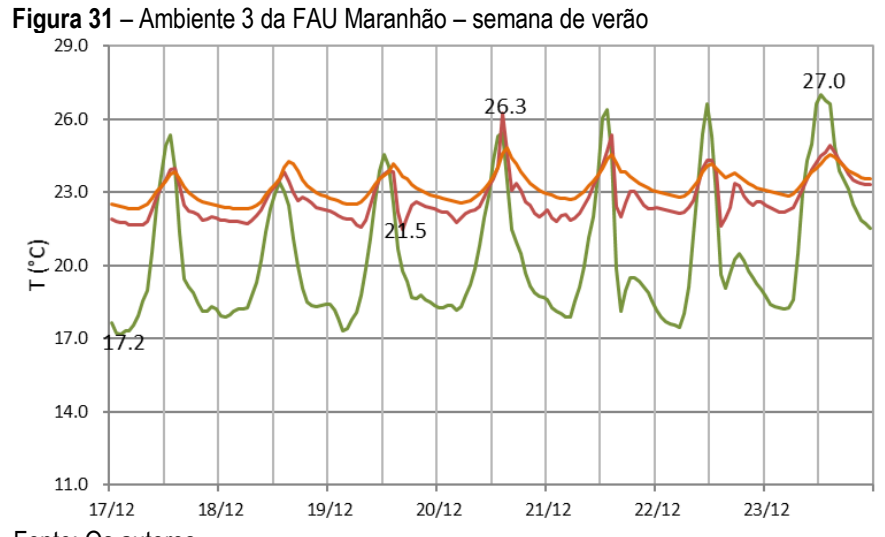

Fonte: Os autores

Assim como pôde ser observado no ambiente 2, a análise anual de desconforto térmico indicou curtos períodos de desconforto por calor, no período de outubro a março, e períodos mais longos de desconforto por frio, no período de maio a setembro. Preponderaram, de qualquer forma, os períodos em situação de conforto térmico, durante todo o ano. 
Figura 32 - Análise anual de desconforto para o ambiente 3 (FAU Maranhão)

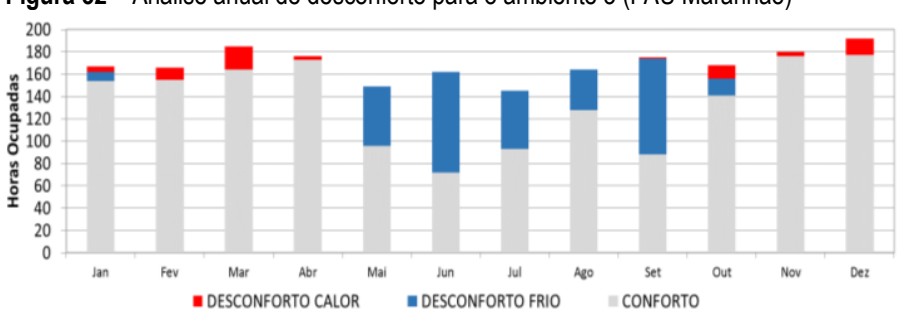

Fonte: Os autores

\section{Conclusões}

O presente trabalho apresenta uma análise de desempenho térmico do edifício da FAU Maranhão em momentos históricos distintos, retratando sua resposta térmica frente a mudanças de clima, entorno construído, cargas internas, padrões de ocupação e operação.

Os resultados das simulações computacionais mostram que a elevada massa térmica da envoltória, o pé-direito alto, a presença do ático e de diversos elementos externos de sombreamento contribuem para a boa resposta térmica da edificação, reduzindo a oscilação da temperatura interna e garantindo elevados níveis de conforto térmico, mesmo após a mudança de uso, de residencial para acadêmico.

A alteração do entorno, trazida pelas construções de elevado gabarito, não traz impactos significativos nos ganhos de calor pela envoltória, pois essa já é adequadamente sombreada, mas prejudica a ventilação natural dos ambientes internos. Também contribui para isto a redução dos ventos observada no arquivo climático. Tal fato evidencia a complexidade de mudança de função de uma edificação ao longo de sua história, que também deve vir acompanhada de um estudo técnico detalhado, de forma a garantir condições adequadas de salubridade e conforto, em amplo aspecto.

Observa-se, de uma forma geral, que o desempenho térmico dos ambientes analisados traz bons resultados de conforto térmico aos usuários da edificação, sendo preponderante os períodos do ano em que os ocupantes se encontram em situação de conforto, considerando o uso atual da edificação. Tais resultados fazem sobressaltar, de forma positiva, a resiliência das técnicas e dos materiais construtivos utilizados em edifícios históricos como a FAU Maranhão.

Até o presente momento, poucos estudos se endereçam ao objetivo de analisar a resposta térmica de edifícios históricos brasileiros. Uma abordagem qualitativa dos resultados deste estudo permite destacar questões importantes sobre o desempenho térmico e peculiaridades referentes à resiliência de edificações históricas que passam por modificações de uso ao longo de sua história. Quando se trata de escalas de tempo que não se restringem ao momento presente, ressalta-se que uma atenção especial deve ser dada a alterações de clima e entorno e sua relação com componentes construtivos, técnicas e materiais, de forma a preservar as características positivas da edificação e garantir sua resiliência quanto à resposta térmica. Mudanças de uso também requerem cuidados com novas fontes de calor advindas de cargas internas pois, além de gerar mudanças significativas nos fluxos de calor, tais fontes podem exigir maiores taxas de ventilação, visando garantir não somente o bom desempenho térmico, mas também a salubridade do ambiente.

Neste contexto, o presente trabalho propõe uma abordagem metodológica para avaliação de desempenho térmico de edificações históricas. Dentro da abordagem proposta, ressalta-se a importância do resgate de dados climáticos, elementos do entorno e padrões de uso e operação da edificação condizentes com o momento histórico analisado, de forma a evitar a adoção de critérios descontextualizados e anacrônicos. A adoção da simulação computacional em software específico mostrase uma abordagem válida, apesar das bibliotecas dessas ferramentas restringirem-se a dados de elementos e componentes construtivos presentes em edificações contemporâneas. Pode-se concluir, portanto, que o resgate histórico aliado ao estudo de desempenho térmico tornase essencial para garantir a veracidade dos resultados.

\section{Referências}

ADHIKARI, R. S.; LUCCHI, E.; PRACCHI, V. Energy modelling of historic buildings: applicability, problems and compared results. In: EUROPEAN WORKSHOP ON CULTURAL HERITAGE PRESERVATION, 3., 2013, Bolzano. Proceedings... Bolzano/Bozen, Italy: EWCHP, 2013.

ASHRAE - AMERICAN SOCIETY OF HEATING, REFRIGERATING AND AIR CONDITIONING ENGINEERS.

ANSI/ASHRAE 55-2004: Thermal environmental conditions for human occupancy. Atlanta, EUA: American Society of Heating, Refrigerating and Air-Conditioning Engineers, 2004.

ANSI/ASHRAE 55-2013: Thermal environmental conditions for human occupancy. Atlanta, EUA: American Society of Heating, Refrigerating and Air-Conditioning Engineers, 2013. 
EDITORES, Os. 30 anos de pós-graduação e Centenário do Edifício Vila Penteado. Pós. Revista do Programa de Pós-Graduação em Arquitetura e Urbanismo da FAUUSP, São Paulo, v. 12, p. 148-150, dec. 2002. ISSN 2317-2762.

doi:http://dx.doi.org/10.11606/issn.2317-2762.v12i0p148-150.

EERE - ENERGY EFFICIENCY AND RENEWABLE ENERGY. EnergyPlus simulation software. US Department of Energy.

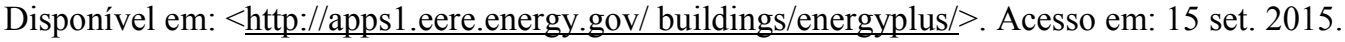

FAU-USP - FACULDADE DE ARQUITETURA E URBANISMO DA UNIVERSIDADE DE SÃO PAULO. Plano Diretor: FAUUSP. Disponível em: $<$ http://www.fau.usp.br/fau/administracao/congregacao/planodiretor/site antigo/anterior/downloads.

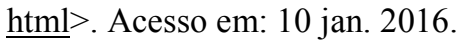

FREIXANET, V. A. F.; VIQUEIRA, M. R. Ventilación natural: cálculos básicos para arquitectura. Azcapotzalco, México: Universidad Autónoma Metropolitana, 2004.

INMETRO - INSTITUTO NACIONAL DE METROLOGIA, NORMALIZAÇÃO E QUALIDADE INDUSTRIAL. RTQ-C: Regulamento Técnico da Qualidade para o nível de eficiência energética de edificações comerciais, de serviços e públicas. INMETRO, 2013. Disponível em: < http://www.pbeedifica.com.br/sites/default/files/projetos/etiquetagem/comercial/downloads/ Port372-2010_RTQ Def_Edificacoes-C_rev01.pdf $>$.

KNOP, S.; CUNHA, E. G. Evaluation of the thermal performance of historic building with new use in the city of Pelotas. In: BUILDING SIMULATION AND OPTIMIZATION, 2012, Loughbourough. Proceedings... Loughbourough, UK: IBPSA, 2012.

KOOGEI - TOKYO POLYTECHNIC UNIVERSITY. Tokyo Politechnic University: New Frontier of Education and Research in Wind Engineering. Disponível em: <http://www.wind.arch.t-kougei.ac.jp/system/eng/>. Acesso em: 27 nov. 2015.

LIMA, Eliana Costa; LEDER, Solange Maria. Conforto ambiental e eficiência energética na reciclagem de edifícios para habitação de interesse social. PARC Pesquisa em Arquitetura e Construção, Campinas, SP, v. 3, n. 2, p. 50-62, out. 2012. ISSN 19806809. doi:http://dx.doi.org/10.20396/parc.v3i2.8634567.

MARTINS, M. L. R. R. (Org.) Vila Penteado 1902-2012. São Paulo, SP: Pós-Graduação 40 Anos, FAUUSP, 2012.

MENDES, N. et al. Uso de instrumentos computacionais para análise do desempenho térmico e energético de edificações no Brasil. Ambiente Construído, v. 5, n. 4, p. 47-68, 2005.

MEYER, R. M. P.; GROSTEIN, D.; BIDERMAN, C. São Paulo metrópole. São Paulo, SP: EDUSP, 2004.

NASCIMENTO, C. B. Deterioração de forro em estuque reforçado com ripas vegetais: o caso "Vila Penteado" - FAU-USP. 2002, 265p. Dissertação (Mestrado em Engenharia) - Escola Politécnica da Universidade de São Paulo, São Paulo, SP, 2002.

RESULI, P.; DERVISHI, S. Thermal performance of cultural heritage Italian housing in Albania. Energy Procedia, v. 78, p. 753758, nov. 2015. doi: http://dx.doi.org/10.1016/ j.egypro.2015.11.087.

RORIZ, M. Climatic data of cities in Brazil. ANTAC - Associação Nacional de Tecnologia do Ambiente Construído. Grupo de Trabalho sobre Conforto e Eficiência Energética de Edificações. Relatório Interno. Disponível em:

$<$ http://www.labeee.ufsc.br/downloads/arquivos-climaticos/formato-epw >. Acesso em: 22 nov. 2012.

SEDOVIC, W.; GOTTHELF, J. H. Paradox to paradigm: sustainability and performance of heritage buildings. In: INTERNATIONAL CONFERENCE OF NATIONAL TRUSTS, 14. 2011, Victoria. Proceedings... Victoria, BC, Ottawa: National Trust for Canada, 2011.

SEGNINI JUNIOR, Francisco. O projeto arquitetônico e qualidade da edificação. Pós. Revista do Programa de Pós-Graduação em Arquitetura e Urbanismo da FAUUSP, São Paulo, n. 24, p. 162-173, dec. 2008. ISSN 2317-2762. doi:http://dx.doi.org/10.11606/issn.2317-2762.v0i24p162-173.

SILVA, H. A. A. et al. A consolidação dos Forros da Vila Penteado: em estuque estruturado por fasquias de juçara. Revista Brasileira de Arqueometria, Restauração e Conservação, v. 1, n. 6, p. 305-308, 2007. 
SILVA, Hugo Entradas; HENRIQUES, Fernando Manuel Anjos. Análise microclimática de um edifício histórico em clima temperado: limites sustentáveis para a correta conservação dos materiais. Ambient. constr., Porto Alegre, v. 15, n. 2, p. 65-77, June 2015. doi:http://dx.doi.org/10.1590/s1678-86212015000200014.

MAGNOLI, Miranda Maria Esmeralda Martinelli. Eu não tenho boa memória, mas conheço gente que tem uma memória!!!..[Entrevista a Jonathas Magalhães Pereira da Silva]. Paisagem e Ambiente, São Paulo, FAU/USP, n. 21, p. 13-42, 2006.

SOARES, I. S. R. Análise do desempenho aplicada à preservação predial: o caso do edifício Vila Penteado. São Paulo, 2012, 392p. Dissertação (Mestrado em Arquitetura e Urbanismo). Faculdade de Arquitetura e Urbanismo da Universidade de São Paulo, São Paulo, SP, 2012.

\section{${ }^{1}$ Leticia de Oliveira Neves}

Arquiteta e Urbanista. Professora Doutora na UNICAMP. Doutora em Arquitetura, Tecnologia e Cidade pela Faculdade de Engenharia Civil, Arquitetura e Urbanismo da UNICAMP. Endereço postal: Av. Albert Einstein, 951, Campinas, SP, Brasil, 13083852.

\section{${ }^{2}$ Rodrigo Dias Machado}

Arquiteto e Urbanista. Graduado na Faculdade de Arquitetura e Urbanismo da USP. Endereço postal: Rua Monsenhor Soares, 763, Itapetininga, SP, Brasil, 18200-009.

\section{${ }^{3}$ Rodrigo Cavalcante}

Arquiteto e Urbanista. Aluno regular de mestrado do Programa de Pós-Graduação em Arquitetura, Tecnologia e Cidade da UNICAMP. Mestre em Arquitetura e Urbanismo pela Faculdade de Arquitetura e Urbanismo da USP. Endereço postal: Av. Pedro Severino Junior 366, conj. 85, São Paulo, SP, Brasil, 04310-060. 